\title{
Osteoconductivity of Hydrophilic Surfaces of Zr-9Nb-3Sn Alloy with Hydrothermal Treatment
}

\author{
Mansjur Zuldesmi ${ }^{1,2}$, Kensuke Kuroda ${ }^{3}$, Masazumi Okido ${ }^{3}$, Masato Ueda ${ }^{4}$, \\ Masahiko Ikeda ${ }^{4}$ \\ ${ }^{1}$ Department of Materials Science \& Engineering, Graduate School of Engineering, Nagoya University, \\ Nagoya, Japan \\ ${ }^{2}$ Department of Mechanical Engineering, Manado State University (UNIMA), Indonesia \\ ${ }^{3}$ EcoTopia Science Institute, Nagoya University, Nagoya, Japan \\ ${ }^{4}$ Faculty of Chemistry, Materials and Bioengineering, Kansai University, Suita, Japan \\ Email: mzuldesmi@yahoo.com
}

Received 13 March 2015; accepted 3 June 2015; published 8 June 2015

Copyright (C) 2015 by authors and Scientific Research Publishing Inc.

This work is licensed under the Creative Commons Attribution International License (CC BY).

http://creativecommons.org/licenses/by/4.0/

\section{(c) (i) Open Access}

\begin{abstract}
Zirconium and its alloys are more suitable materials for implant surgery to be performed in a magnetic resonance imaging scanner compared with other implant materials. Although they have high anticorrosion properties in the body, as do titanium and its alloys, they have little use as implants in contact with bone because of their low osteoconductivity (bone-implant contact ratio). To improve the osteoconductivity of zirconium, niobium, and $\mathrm{Zr}-9 \mathrm{Nb}-3 \mathrm{Sn}$ alloy, we applied a single-step hydrothermal surface treatment using distilled water at a temperature of $180^{\circ} \mathrm{C}$ for $3 \mathrm{~h}$. The hydrothermally treated samples were stored in a $\times 5$ phosphate-buffered saline (PBS(-)) solution to keep or to improve the water contact angle (WCA), which has a strongly positive effect on osteoconductivity. The specimen surfaces were characterized using scanning electron microscopy, $\mathrm{X}$-ray diffraction, $\mathrm{X}$-ray photoelectron spectroscopy, surface roughness, and contact angle measurement using a $2 \mu \mathrm{L}$ droplet of distilled water. The relationship between WCA and osteoconductivity for various surface modifications was examined using in vivo tests. The results showed that a superhydrophilic surface with a WCA $\leq 10^{\circ}$ and a high osteoconductivity of up to $40 \%$ in cortical bone, about four times higher than the as-polished $\mathrm{Zr}-9 \mathrm{Nb}-3 \mathrm{Sn}$ and its pure alloy elements, was provided by the combination of hydrothermal surface treatment and storage in $\times 5$ PBS(-).
\end{abstract}

\section{Keywords}

Zirconium Alloys, Hydrothermal, Hydrophilic, in Vivo, Osteoconductivity 


\section{Introduction}

Recently, magnetic resonance imaging (MRI) has been widely used as a diagnostic tool in orthopedics and brain surgery. However, defects and distortions sometimes appear in the MRI images when metallic orthopedic implants are inserted into a patient's body because of differences in the magnetic susceptibilities of the metals and living tissues [1]. To minimize the artifacts, medical devices with magnetic susceptibility near to living tissues are required. Zirconium (Zr) becomes more suitable for surgery performed in an MRI scanner because its magnetic susceptibility is closer to that of living tissue than stainless steel, Co-Cr alloys, and titanium. Therefore, Zr-based alloys such as Zr-Nb have been developed [2] [3]. The preference for using Zr and its alloys for surgical implants is influenced by their favorable material properties, acceptable mechanical strength, and high corrosion resistance. Niobium, in and of itself, is highly corrosion resistant, in addition to being a strengthener to Zr. $\mathrm{Zr}$ and its alloys have also been shown to be nontoxic and biocompatible [4] [5]. However, the untreated surface of $\mathrm{Zr}$ and its alloys offers low osseointegration characteristics with poor bone-forming properties [6]. As is well known, surface roughness and hydrophilicity are two crucial factors that influence the biological response at the interface between the bone tissue and the implant, and consequently, osseointegration [7]-[10]. Therefore, surface modifications have been employed to improve the osteoconductivity of the $\mathrm{Zr}$ and its alloys. Anodizing is a simple and economical method of obtaining a uniform surface oxide film, regardless of the specimen geometry. However, in our previous studies, anodizing was not shown to be effective in producing a hydrophilic surface on pure $\mathrm{Zr}$ and $\mathrm{Nb}$ specimens. In contrast, hydrothermal treatment became a beneficial surface modification that can improve osteoconductivity because it created a hydrophilic surface not only on pure Ti, but also on pure $\mathrm{Zr}$ and $\mathrm{Nb}$ surfaces [11] [12]. In addition, it is necessary to keep maintain the hydrophilic surface condition before implantation. In those previous researches, we also detected that stored in $\times 5$ PBS $(-)$ before and after surface treatment improved the surface hydrophilicity of pure Ti for longer time. Therefore, in this study, we investigated whether a hydrothermal treatment and storage in $\times 5$ PBS $(-)$ solution were also beneficial methods in improving the osteoconductivity of Zr-9Nb-3Sn and its alloy. Osteoconductivity was evaluated by in vivo testing.

\section{Materials and Methods}

\subsection{Sample Preparation}

Two different sample shapes, made from Zr-9Nb-3Sn, pure Zr, and pure Nb, were used to characterize the surface and to evaluate osteoconductivity in an in vivo test. Plates $(12 \mathrm{~mm} \times 4 \mathrm{~mm})$ were used for surface characterization and rods $(\varnothing 2 \mathrm{~mm} \times 5 \mathrm{~mm})$ for in vivo testing. The samples were abraded with emery paper up to \#2000, polished by $\mathrm{Al}_{2} \mathrm{O}_{3}$ particles with a size of $0.05 \mu \mathrm{m}$, degreased with ethanol for $5 \mathrm{~min}$ in an ultrasonic cleaner, and finally dried at room temperature. After that, the following processes were applied to the samples.

\subsection{Anodic Oxidation}

Zr-9Nb-3Sn, pure Zr, Nb samples, and a Pt coil were set as the anode and cathode, respectively. A reference electrode was not used. The electrolyte solution was $0.1 \mathrm{M} \mathrm{H}_{2} \mathrm{SO}_{4}$ and was stirred by a magnetic stirrer at a constant temperature $\left(25^{\circ} \mathrm{C}\right)$. The anodizing voltage was increased from $0 \mathrm{~V}$ to a final voltage of $150 \mathrm{~V}$ at a rate of $0.1 \mathrm{Vs}^{-1}$, which was chosen to prevent sparking. After anodizing, the samples were sterilized using an autoclave unit at $121^{\circ} \mathrm{C}$ for $20 \mathrm{~min}$.

\subsection{Hydrothermal Process}

The hydrothermal process was applied to Zr-9Nb-3Sn, pure Zr, and Nb samples after polishing. The samples were immersed in a beaker containing $300 \mathrm{~mL}$ distilled water and placed in a hydrothermal unit. The temperature of the hydrothermal vessel was set at $180^{\circ} \mathrm{C}$ and maintained at this condition for 180 min [11]. After hydrothermal treatment, the beaker was removed from the hydrothermal unit and cooled naturally to room temperature.

\subsection{Sample Storage}

The samples were stored under three storage media (at room temperature): in air, in distilled water and in five times concentrated phosphate buffered saline $(\times 5 \mathrm{PBS}(-))$. The composition of $\times 1 \mathrm{PBS}(-)$ was $\left(\right.$ in $\left.\mathrm{g} \cdot \mathrm{L}^{-1}\right) 8 \mathrm{NaCl}$, $0.2 \mathrm{KCl}, 1.44 \mathrm{Na}_{2} \mathrm{HPO}_{4}, 0.24 \mathrm{KH}_{2} \mathrm{PO}_{4}$, and $<0.1$ diethyl dicarbonate. The storing period of samples in the dif- 
ferent media was carried out up to 168 hours (h). For in vivo test, we used untreated and hydrothermally treated samples after $24 \mathrm{~h}$ immersed in $\times 5$ PBS(-).

\subsection{Surface Characterization}

The surface morphologies of the treated and untreated samples were observed by scanning electron microscopy (SEM). The crystal structure and chemical composition of Zr-9Nb-3Sn were determined by thin-film X-ray diffraction (XRD) and X-ray photoelectron spectroscopy (XPS), respectively. The surface roughness measurements were obtained by means of contactless probing using a confocal laser scanning microscope with a measurement area of $150 \mu \mathrm{m} \times 112 \mu \mathrm{m}$. The arithmetical mean of the profile deviations (Ra) defined the surface roughness. The water contact angle (WCA) was estimated using a $2 \mu \mathrm{L}$ droplet of distilled water.

\subsection{In Vivo Testing}

In this study, as-polished samples and hydrothermaled samples after immersed in a $\times 5$ PBS(-) solution were subjected to in vivo testing. Six rat tibias were used for each in vivo test. The experimental procedure for my in vivo study was similar to that described in a previous report [13]. Prior to surgery, all implants (metals rods) were cleaned ultrasonically in distilled water, sterilized in a steam autoclave, and immersed in a chlorhexidine gluconate solution. The 340 - 400 g 10-week-old male Sprague Dawley rats (Charles River Japan, Inc.) were used in this experiment. The animals were kept in quarantine for 7 days. The rats were anesthetized using the pentobarbital (25 - $30 \mathrm{mg} \cdot \mathrm{kg}^{-1}$ ) and the incision sites (right and left) and surrounding area were shaved and cleaned with povidine iodine solution and $70 \%$ ethanol. Slightly oversized holes, which did not pass completely through the bone, were created with a low speed rotary drill under profuse saline irrigation, and the bone debris was washed away with saline. Eventually, implants were inserted in these holes, and Penicillin G was administered for the prevention of infection. The subcutaneous tissue and skin were then closed and sterilized with povidine iodine solution. After surgery, rats were housed individually in polycarbonate cages, and monitored daily for any complications. Rats were sacrificed after 14 days, and the implants with their surrounding tissue were retrieved. The specimens were fixed in $10 \%$ neutral buffered formalin solution, rinsed in distilled water, dehydrated in a graded series of ethanol, and embedded in methyl methacrylate. Following polymerization, each implant block was sectioned to $20 \mu \mathrm{m}$ thick slices. The final sections were stained with toluidine blue. The cancellous bone and the interface between the implant and the cortical bone were observed by optical microscopy. The sum of the linear bone contact with the implant surface was measured and was expressed as a percentage over the entire implant length (the bone-implant contact ratio, $R_{\mathrm{B}-\mathrm{I}}$ ) in the cortical bone part. Significant differences in $\mathrm{R}_{\mathrm{B}-\mathrm{I}}$ were examined statistically using the Tukey-Kramer method. Results were regarded as significant when $p<0.05$.

\section{Results and Discussion}

\subsection{Surface Characteristics}

It is well known that surface roughness plays an important function in the biological response of biomaterial surfaces. Using previous research as a reference, it was observed that the osteoconductivity of $\mathrm{TiO}_{2}$ coatings was enhanced by a fine surface finish $(\mathrm{Ra} / \mu \mathrm{m}<0.1)$ [14]. SEM displayed identical surface morphologies in all treated samples, which had smooth surfaces with $\mathrm{Ra} / \mu \mathrm{m}$ about 0.1 or less, similar to the as-polished samples (as shown in Figure 1).

The oxidation layer was formed during surface treatment (anodizing and hydrothermal). It was confirmed by XRD analysis for all treated samples as shown in Figure 2. For the surface-treated of Zr-9Nb-9Sn alloy, the $\mathrm{ZrO}_{2}$ oxide peak was distinctly visible on the surface. This peak was also seen on the pure $\mathrm{Zr}$ surface for several of the surface treatments were applied. However, the peak intensity of $\mathrm{Nb}_{2} \mathrm{O}_{5}$ oxide became relatively weak and was almost undetectable for the Zr-9Nb-3Sn and pure $\mathrm{Nb}$ metal surfaces and considered as an amorphous oxide [15].

\subsection{Surface Hydrophilicity}

Surface hydrophilicity may play a major role in the adsorption of proteins onto the surface, as well as cell adhesion 
(a)

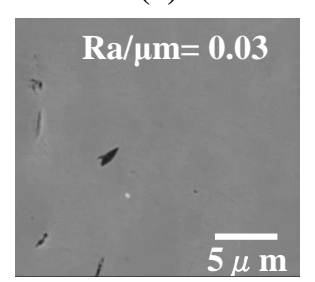

(1)

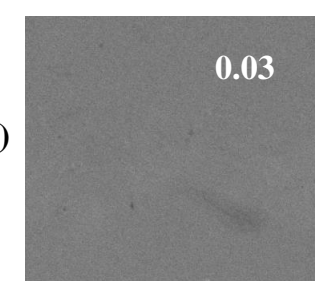

0.04

(3)

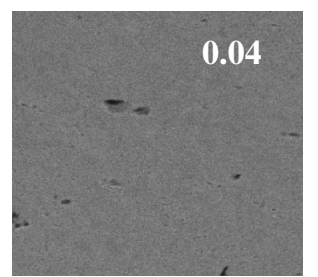

(b)
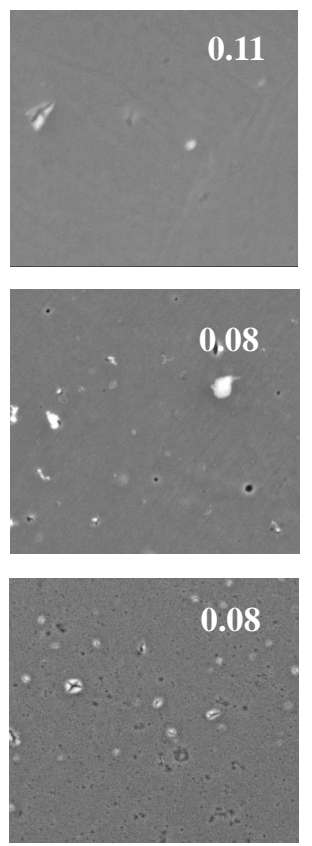

(c)
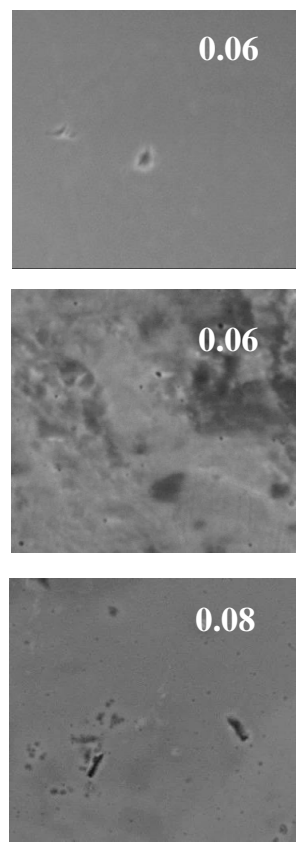

(d)

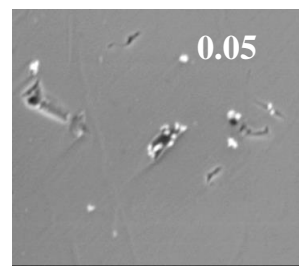

0.04

\%
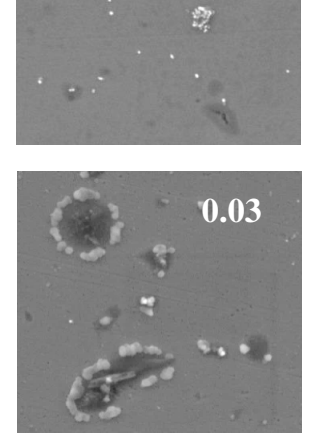

Figure 1. Surface morphology and surface roughness (Ra/ $\mu \mathrm{m}$ ) of (1) Zr-9Nb-3Sn, (2) Zr, and (3) Nb samples, each of which was (a) as-polished; (b) as-anodized in a $\mathrm{H}_{2} \mathrm{SO}_{4}$ solution; (c) anodized + hydrothermaled; and (d) as-hydrothermaled in distilled water at $180^{\circ} \mathrm{C}$ for $180 \mathrm{~min}$.
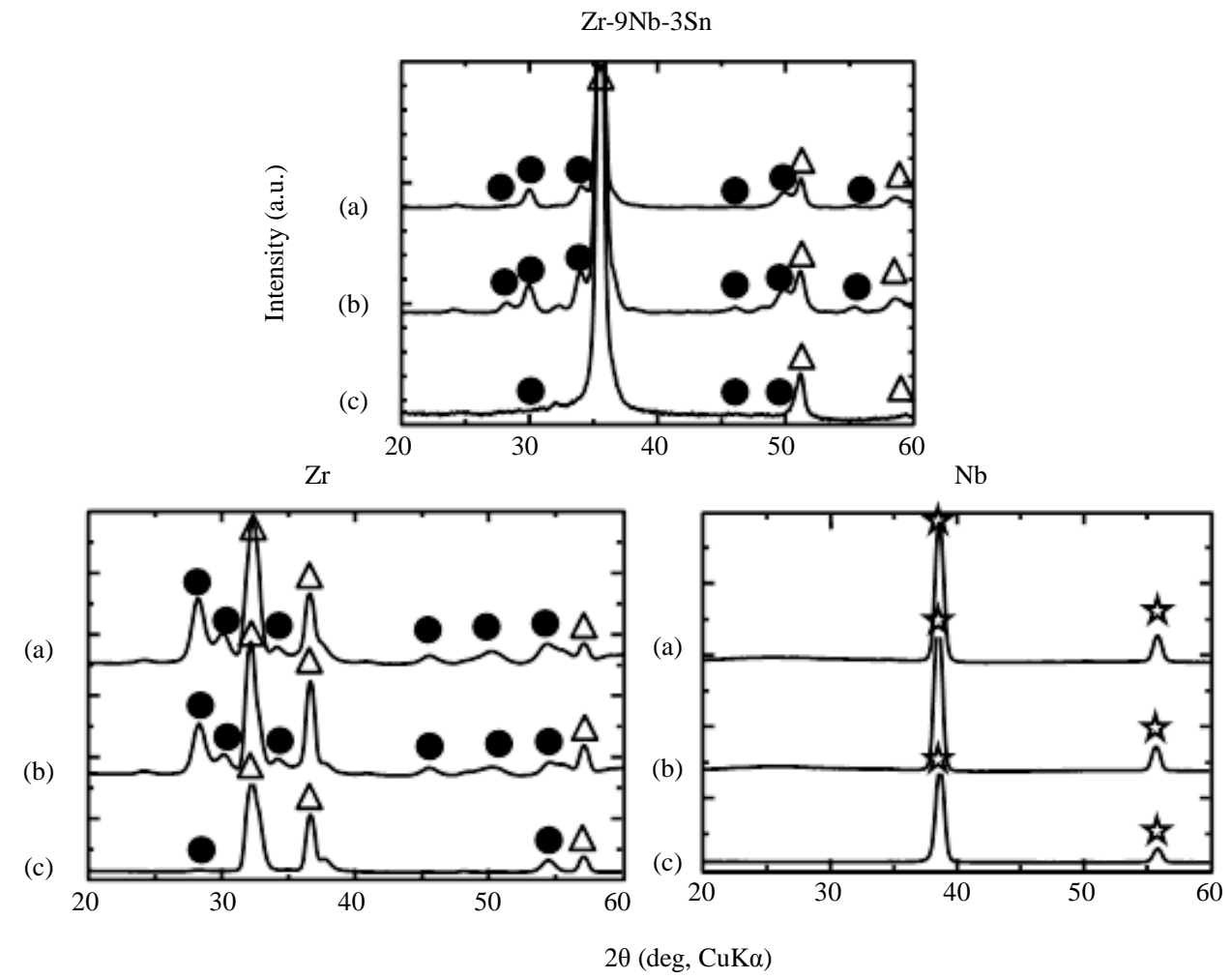

Figure 2. XRD patterns of $\mathrm{Zr}-9 \mathrm{Nb}-3 \mathrm{Sn}, \mathrm{Zr}$, and $\mathrm{Nb}$ using different treatments: (a) as-anodized in $\mathrm{H}_{2} \mathrm{SO}_{4}$ solution; (b) anodized + hydrothermaled; and (c) as-hydrothermaled in distilled water at $180^{\circ} \mathrm{C}$ for 180 min. Symbols: $\bar{\kappa}=\mathrm{Nb}, \Delta=\mathrm{Zr}$, and $\bullet=\mathrm{ZrO}_{2}$. 
[15]. Cell adhesion is generally better on hydrophilic surfaces [16]. In our results, a similar trend was observed for pure $\mathrm{Zr}$, Nb, and Zr-9Nb-3Sn. Anodizing did not provide a significant enhancement of the hydrophilicity of all samples. This can be seen in Figure 3, where despite the WCA of Zr-9Nb-3Sn and its alloy elements (Zr and $\mathrm{Nb}$ ) decreasing after anodizing, they still produced hydrophobic surfaces with WCA $>60^{\circ}$. The high WCAs of pure $\mathrm{Zr}$ and $\mathrm{Nb}$ after anodizing (higher than $60^{\circ}$ ) probably influenced the hydrophobicity of this Zr-9Nb-3Sn alloy. In contrary, the WCAs of Zr-9Nb-3Sn and its alloy elements decreased significantly after hydrothermal treatment with and without anodizing, becoming lower than $30^{\circ}$. This means that the hydrothermal treatment produced hydrophilic surfaces for pure $\mathrm{Zr}$ and Nb, as well as for Zr-9Nb-3Sn alloy.

After obtaining the hydrophilic surface by hydrothermal treatment, it is important to maintain this condition before implantation because the hydrophilicity can change over time. In Figure 4, untreated and treated samples show the same tendency after storing in various media. When the samples were stored in air and distilled water for longer time periods, their WCAs increased remarkably and their surfaces became more hydrophobic. This condition is not good and unsuitable for implantation.

The adsorption of contaminants from the air or solution was probably one of the reasons for this increase in the WCAs. In contrary, the surface hydrophilicity of untreated and treated Zr-9Nb-3Sn, pure Zr, and Nb were significantly improved (their WCAs decreased notably) when stored in $\times 5 \mathrm{PBS}(-)$ and kept this condition from $24 \mathrm{~h}$ above. This is because of adsorbed solute ions in PBS(-), such as $\mathrm{Na}$ and $\mathrm{Cl}$ [17]. The surface of hydrothermaled samples after stored in $\times 5$ PBS(-) show the most hydrophilic compared with as-polished and as-anodized samples. It means that storing in $\times 5$ PBS(-) is effective in maintaining the super hydrophilic surfaces on hydrothermaled Zr-9Nb-3Sn, pure Zr, and Nb samples, as well as on those of pure $\mathrm{Ti}$ [11].

\subsection{XPS Analysis}

$\mathrm{Zr}$ is well known for its strong bond to atmospheric elements, such as oxygen, hydrogen, nitrogen, and carbon. Adsorption of hydrocarbon (C-H) always occurs under normal conditions in air or solution containing organic contaminants. Adsorption of $\mathrm{C}-\mathrm{H}$ as a surface contaminant can occur during storage after surface treatment. The hydroxyl $\left(\mathrm{OH}^{-}\right)$group is another factor that can influence the surface hydrophilicity, in a similar manner as adsorbed $\mathrm{C}-\mathrm{H}$. As shown in Figure 5, XPS analysis showed the change in adsorption of $\mathrm{C}-\mathrm{H}$ and $\mathrm{OH}^{-}$groups on the surface hydrophilicity (WCA) of samples after several different surface treatments. Spectrum analysis was performed as described in our previous report [12]. As for pure $\mathrm{Zr}$ and $\mathrm{Nb}$, the adsorption of $\mathrm{C}-\mathrm{H}$ for the Zr-9Nb-3Sn alloy decreased significantly after hydrothermal treatment, in the same manner as pure Ti [11]. By cleaning the surfaces to remove contamination, the hydrophilicity of pure $\mathrm{Zr}, \mathrm{Nb}$, and $\mathrm{Zr}-9 \mathrm{Nb}-3 \mathrm{Sn}$ improved notably. This result agrees with an earlier study, which reported that surface contamination increased the WCA

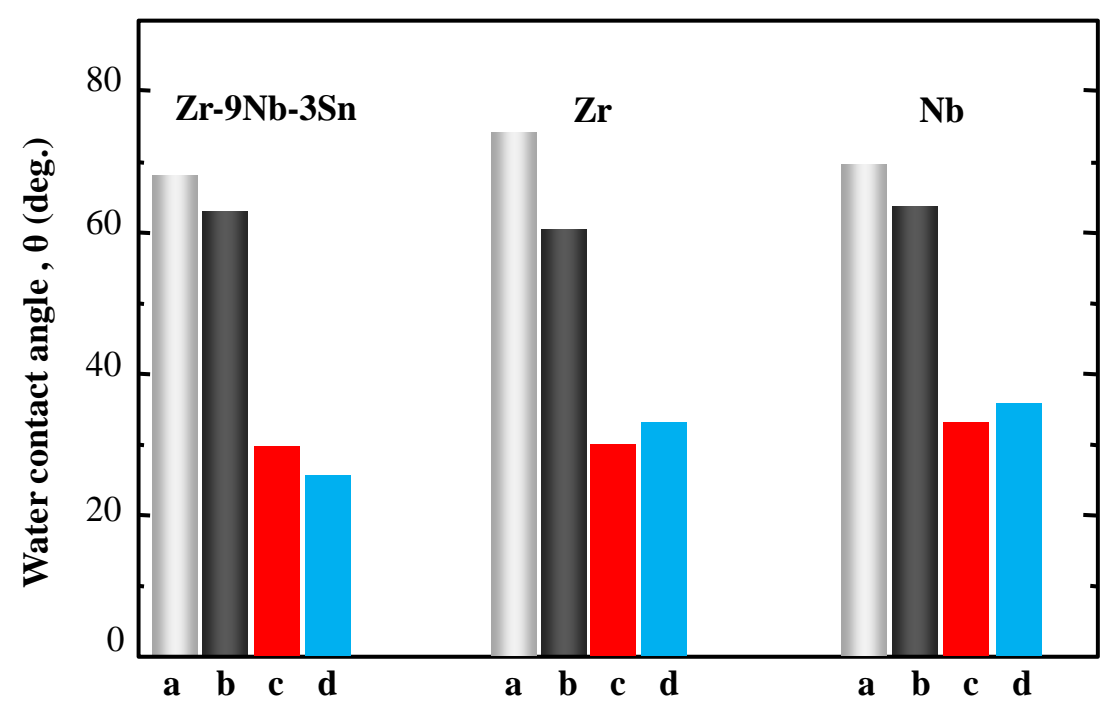

Figure 3. WCA of Zr-9Nb-3Sn, Zr, and Nb samples with various surface modifications: (a) as-polished; (b) as-anodized in a $\mathrm{H}_{2} \mathrm{SO}_{4}$ solution; (c) anodized + hydrothermaled; and (d) as-hydrothermaled in distilled water at $180^{\circ} \mathrm{C}$ for $180 \mathrm{~min}$. 


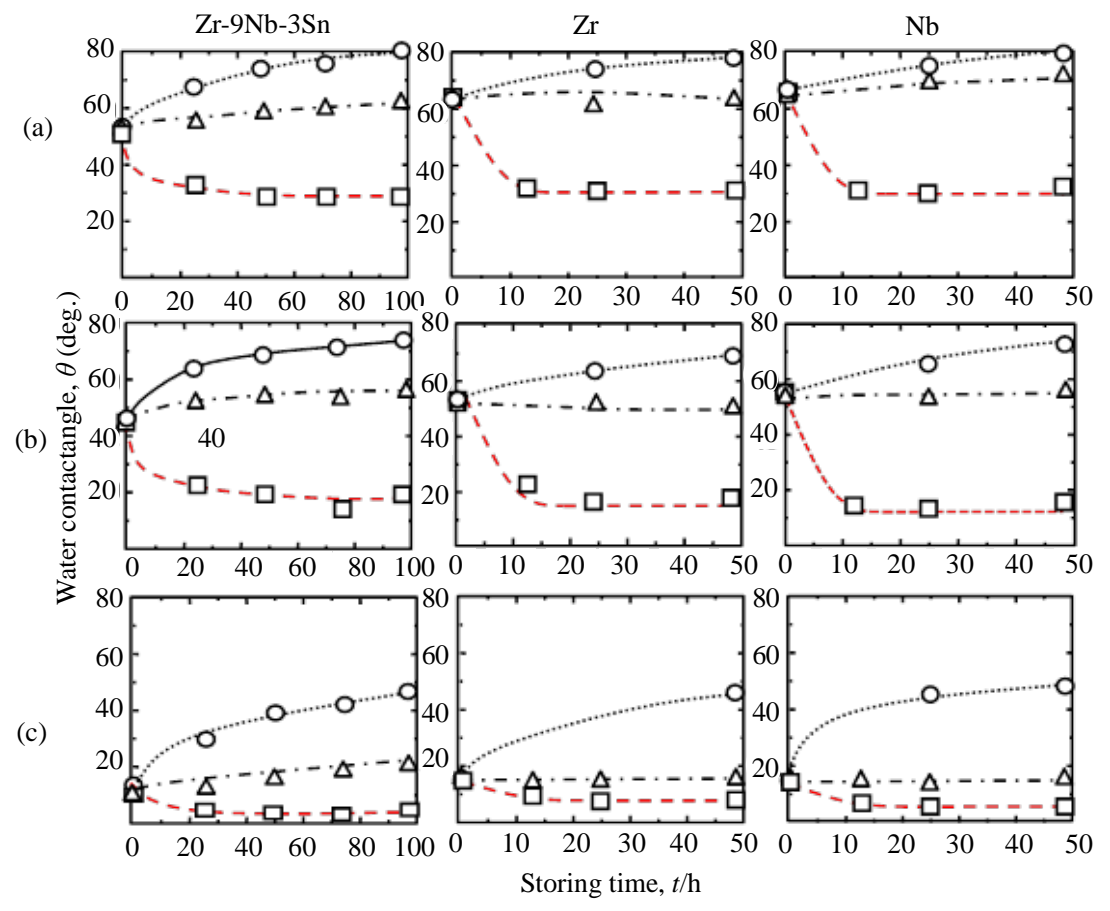

Figure 4. Relationship between the WCA and periods of Zr-9Nb-3Sn, Zr, and Nb with various surface modifications: (a) as-polished; (b) as anodized in a $\mathrm{H}_{2} \mathrm{SO}_{4}$ solution; and (c) as-hydrothermaled after stored: $\circ$ in air, $\triangle$ in distilled water, and $\square$ in $\times 5$ PBS $(-)$.

\section{Zr-9Nb-3Sn}
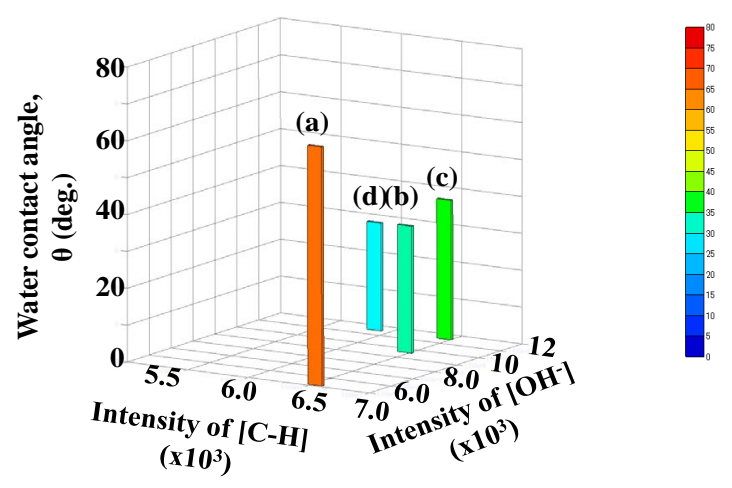

Zr

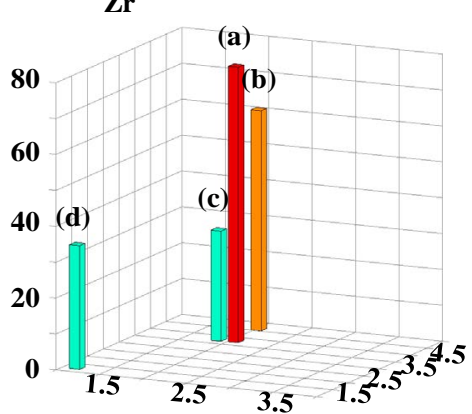

Nb

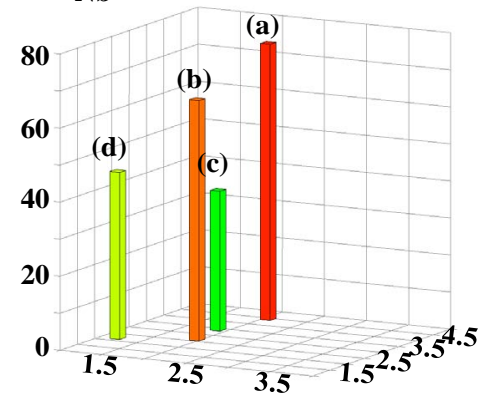

Figure 5. Quantitative relationship between the surface $\mathrm{OH}^{-}$group, adsorbed $\mathrm{C}-\mathrm{H}$, and WCA for single metals of Zr-9Nb-3Sn, Zr, and Nb under different treatment conditions: (a) as-polished; (b) as-anodized; (c) anodized + hydrothermally treated; and (d) hydrothermally treated. The amounts of $\mathrm{OH}^{-}$and $\mathrm{C}-\mathrm{H}$ were calculated from the O1s and C1s spectra from XPS analysis. The color scale in the spectrum represents the range of the WCA. 
and the surface became more hydrophobic [18]. In vitro studies have also indicated that surface contamination reduced cell attachment and spreading [19]. On the other hand, the binding of the $\mathrm{OH}^{-}$group did not have a similar trend for each sample and seemed to be unaffected by the process. However, it depends on the type of hydroxyl group (such as, hydroxyl radical or hydroxyl anion). Therefore, the reduction of the adsorbed $\mathrm{C}-\mathrm{H}$ was the mostly important factor for improvement of the hydrophilicity of hydrothermaled $\mathrm{Zr}-9 \mathrm{Nb}-3 \mathrm{Sn}$, pure $\mathrm{Zr}$, and Nb samples.

\subsection{In Vivo Testing}

As-polished and hydrothermaled samples of Zr-9Nb-3Sn and its alloy elements were used for in vivo testing after being stored for $24 \mathrm{~h}$ in $\times 5 \mathrm{PBS}(-)$. As a reference, the previous in vivo results for $\mathrm{TiO}_{2}$-coated samples with $\mathrm{Ra} / \mu \mathrm{m}<0.1$ are also shown in Figure 6 [20] [21]. It can be seen that by decreasing the WCA the osteoconductivity $\left(\mathrm{R}_{\mathrm{B}-\mathrm{I}}\right)$ of the hydrothermaled samples (Zr-9Nb-3Sn, pure $\mathrm{Zr}$, and $\left.\mathrm{Nb}\right)$ after being stored in $\times 5 \mathrm{PBS}(-)$ became higher by $40 \%$ - $45 \%$ compared with that of the as-polished samples. According to previous reports, surface hydrophilicity influences the adsorption of cell adhesive proteins containing Ag-Gly-Asp (RGD) sequences, such as fibronectin, on the implant surface, and thus enhances the adhesion and spreading of osteoblast precursors on these surfaces [7] [22]. Our results correspond with those of previous in vitro and in vivo studies that detected that osteoblast cell adhesion, differentiation, and early bone formation (osteoconductivity) on implant surfaces were significantly enhanced on hydrophilic surfaces compared with hydrophobic surfaces [23]-[27]. We conclude that the combination of hydrothermal treatment and $\times 5$ PBS(-) immersion is an effective method of enhancing the osteoconductivity of $\mathrm{Zr}-9 \mathrm{Nb}-3 \mathrm{Sn}$, as well as pure alloy elements (pure $\mathrm{Zr}$ and $\mathrm{Nb}$ ), by producing hydrophilic surfaces.

\section{Conclusion}

In the present study, the hydrothermally treated surfaces of Zr-9Nb-3Sn and its pure alloy elements ( $\mathrm{Zr}$ and $\mathrm{Nb}$ ) after storage in $\times 5$ PBS(-) were super hydrophilic with higher osteoconductivity (an increase of $40 \%-45 \%$ ) compared with untreated samples. This suggests that hydrothermal treatment may be a promising surface treatment for improving the osteoconductivity of implant materials such as $\mathrm{Zr}, \mathrm{Nb}$, and $\mathrm{Zr}-9 \mathrm{Nb}-3 \mathrm{Sn}$ alloy in the future. However, further studies are needed to improve our understanding of the effect of surface treatments and hydrophilic surfaces on fibronectin adsorption.

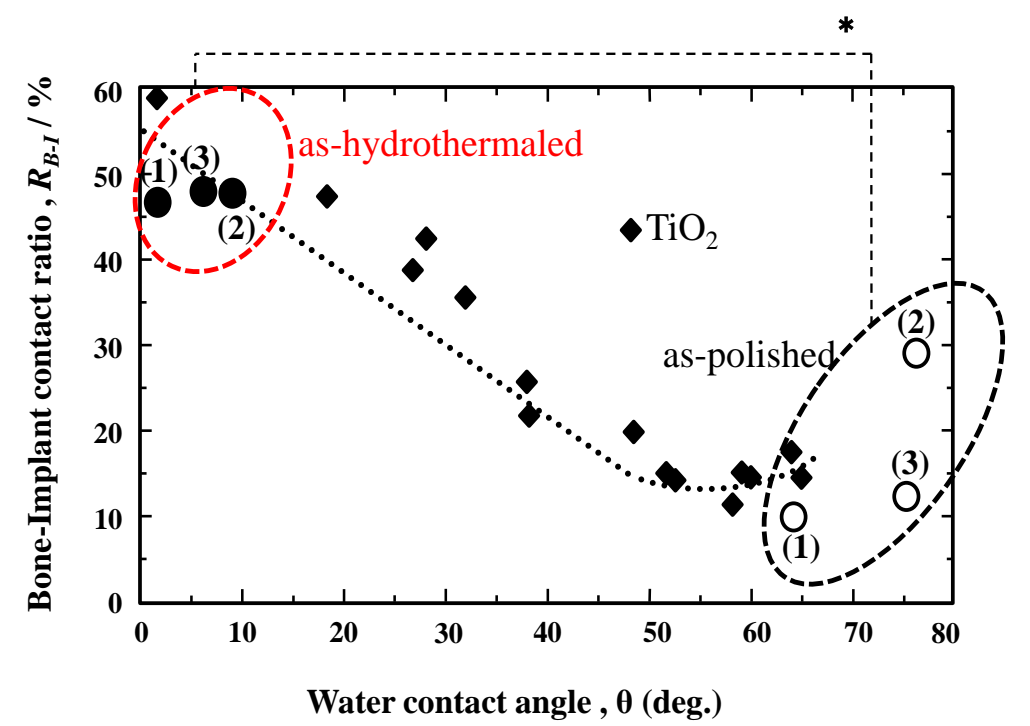

Figure 6. Relationship between $\mathrm{R}_{\mathrm{B}-\mathrm{I}}$ (in cortical bone) and WCA of (1) Zr-9Nb-3Sn; (2) Zr; and (3) Nb samples with various surface modifications and subsequent storage methods: $\bigcirc$ as-polished, $\bullet$ as-hydrothermaled after immersed in $\times 5$ PBS $(-)$ solution and $\bullet$ anodized Ti in different aqueous solutions $(\mathrm{Ra} / \mu \mathrm{m}$ $<0.1) ;{ }^{*} p<0.05$. 


\section{Acknowledgements}

This work was partially supported by an Indonesian Government scholarship from the Directorate General of Higher Education (DIKTI), Project of Advanced Materials Development and Integration of Novel Structured Metallic and Inorganic Materials by the Ministry of Education, Culture, Sports, Science, and Technology (MEXT) of Japan, and a Grant-in Aid for JSPS fellows (No. 25289248, 26630345).

\section{References}

[1] Hanawa, T. (2010) Metals for Medicine. Japan Institute of Metals, Sendai.

[2] N. Nomura, Y. Tanaka, Suyalatu, R. Kondo, H. Doi, Y. Tsutsumi, T. Hanawa, (2009) Effects of Phase Constitution of Zr-Nb Alloys on their Magnetic Susceptibilities. Material Transactions, 50, 2466-2472.

[3] Kondo, R., Nomura, N., Suyalatu, Tsutsumi, Y., Doi, H. and Hanawa, T. (2011) Microstructure and Mechanical Properties of As-Cast Zr-Nb Alloys. Acta Biomaterialia, 7, 4278-4284. http://dx.doi.org/10.1016/j.actbio.2011.07.020

[4] Eisenbart, E., Velten, D., Muller, M., Thull, R. and Breme, J. (2004) Biocompatibility of $\beta$-Stabilizing Elements of Titanium Alloys. Biomaterials, 25, 5705-5713. http://dx.doi.org/10.1016/j.biomaterials.2004.01.021

[5] Yamamoto, A., Honma, R. and Sumita, M. (1998) Cytotoxicity Evaluation of 43 Metal Salts using Murine Fibroblasts and Osteoblastic Cells. Journal of Biomedical Materials Research, 39, 331-340. http://dx.doi.org/10.1002/(SICI)1097-4636(199802)39:2<331::AID-JBM22>3.0.CO;2-E

[6] Le Guehennec, L., Soueidan, A., Layrolle, P. and Amouriq, Y. (2007) Surface Treatments of Titanium Dental Implants for Rapid Osseointegration. Dental Materials, 23, 844-854. http://dx.doi.org/10.1016/j.dental.2006.06.025

[7] Kilpadi, K.L., Chang P.L. and Bellis, S.L. (2001) Hydroxyapatite Binds More Serum Proteins, Purified Integrins, and Osteoblast Precursor Cells than Titanium or Steel. Journal of Biomedical Material Research Part A, 57, 258-267. http://dx.doi.org/10.1002/1097-4636(200111)57:2<258::AID-JBM1166>3.0.CO;2-R

[8] Rupp, F., Scheideler, L., Olshanska, N., de Wild, M., Wieland, M. and Geis-Gerstorfer, J. (2006) Enhancing Surface Free Energy and Hydrophilicity through Chemical Modification of Microstructured Titanium Implant Surfaces. Journal of Biomedical Material Research Part A, 76A, 323-334. http://dx.doi.org/10.1002/jbm.a.30518

[9] Das, K., Bose, S. and Bandyopadhyay, A. (2007) Surface Modifications and Cell-Materials Interactions with Anodized Ti. Acta Biomaterialia, 3, 573-585. http://dx.doi.org/10.1016/j.actbio.2006.12.003

[10] Bigerelle, M., Anselme, K., Noel, B., Ruderman, I., Hardouin, P. and Iost, A. (2002) Improvement in the Morphology of Ti-Based Surfaces: A New Process to Increase in Vitro Human Osteoblast Response. Biomaterials, 23, 1563-1577. http://dx.doi.org/10.1016/s0142-9612(01)00271-x

[11] Zuldesmi, M., Waki, A., Kuroda, K. and Okido, M. (2013) High Osteoconductive Surface of Pure Titanium by Hydrothermal Treatment. Journal of Biomaterials and Nanobiotechnology, 4, 284-290. http://dx.doi.org/10.4236/jbnb.2013.43036

[12] Zuldesmi, M., Waki, A., Kuroda, K. and Okido, M. (2014) Enhancement of Valve Metal Osteoconductivity by One-Step Hydrothermal Treatment. Material Science and Engineering C, 42, 405-411. http://dx.doi.org/10.4236/jbnb.2013.43036

[13] Kuroda, K., Nakamoto, S., Miyashita, Y., Ichino, R. and Okido, M. (2006) Osteoconductivity of HAp Films with Different Surface Morphologies Coated by the Thermal Substrate Method in Aqueous Solutions. Materials Transactions, 47, 1391-1394. http://dx.doi.org/10.2320/matertrans.47.1391

[14] Yamamoto, D., Kawai, I., Kuroda, K., Ichino, R., Okido, M. and Seki, A. (2011) Osteoconductivity of Anodized Titanium with Controlled Micron-Level Surface Roughness. Material Transactions, 52, 1650-1654. http://dx.doi.org/10.2320/matertrans.M2011049

[15] Habazaki, H., Uozumi, M., Konno, H., Shimizu, K., Skeldon, P. and Thompson, G.E. (2003) Crystallization of Anodic Titania on Titanium and Its Alloys. Corrosion Science, 45, 2063-2073. http://dx.doi.org/10.1016/S0010-938X(03)00040-4

[16] Park, J.W., Jang, J.H., Lee, C.S. and Hanawa, T. (2009) Osteoconductivity of Hydrophilic Microstructured Titanium Implants with Phosphate Ion Chemistry. Acta Biomaterialia, 5, 2311-2321. http://dx.doi.org/10.1016/j.actbio.2009.02.026

[17] Yamamoto, D., Arii, K., Kuroda, K., Ichino, R., Okido, M. and Seki, A. (2013) Osteoconductivity of Superhydrophilic Anodized $\mathrm{TiO}_{2}$ Coatings on Ti Treated with Hydrothermal Process. Journal of Biomaterials and Nanobiotechnology, 4, 45-52. http://dx.doi.org/10.4236/jbnb.2013.41007

[18] Baier, R.E., Meyer, A.E., Natiella, J.R. and Carter, J.M. (1984) Surface Properties Determine Bioadhesive Outcomes: Methods and Results. Journal Biomedical Material Research, 18, 337-355. 
http://dx.doi.org/10.1002/jbm.820180404

[19] Vezeau, P., Keller, J. and Wightman, J. (2000) Reuse of Healing Abutments: An in Vitro Model of Plasma Cleaning and Common Sterilization Techniques. Implant Dentistry, 9, 236-246. http://dx.doi.org/10.1097/00008505-200009030-00009

[20] Yamamoto, D., Kuroda, K., Ichino, R. and Okido, M. (2012) Anodic Oxide Coatings on Ti Alloys and Their Osteoconductivity. Material Science Forum, 706-709, 612-616. http://dx.doi.org/10.4028/www.scientific.net/MSF.706-709.612

[21] Yamamoto, D., Iida, T., Arii, K., Kuroda, K., Ichino, R., Okido, M. and Seki, A. (2012) Surface Hydrophilicity and Osteoconductivity of Anodized Ti in Aqueous Solutions with Various Solute Ions. Material Transactions, 53, 19561961. http://dx.doi.org/10.2320/matertrans.M2012082

[22] Schneider, G. and Burridge, K. (1994) Formation of Focal Adhesions by Osteoblasts Adhering to Different Substrata. Experimental Cell Research, 214, 264-269. http://dx.doi.org/10.1006/excr.1994.1257

[23] Buser, D., Broggini, N., Wieland, M., Schenk, R.K., Denzer, A.J. and Cochran, D.L. (2004) Enhanced Bone Apposition to a Chemically Modified SLA Titanium Surface. Journal of Dental Research, 83, 529-533. http://dx.doi.org/10.1177/154405910408300704

[24] Eriksson, C., Nygren, H. and Ohlson, K. (2004) Implantation of Hydrophilic and Hydrophobic Titanium Discs in Rat Tibia: Cellular Reactions on the Surfaces during the First 3 Weeks in Bone. Biomaterials, 25, 4759-4766. http://dx.doi.org/10.1016/j.biomaterials.2003.12.006

[25] Zhao, G., Schwartz, Z., Wieland, M., Rupp, F., Geis-Gerstorfer, J., Cochran, D.L. and Boyan, B.D. (2005) High Surface Energy Enhances Cell Response to Titanium Substrate Microstructure. Journal of Biomedical Materials Research A, 74, 49-58. http://dx.doi.org/10.1002/jbm.a.30320

[26] Yamamoto, H., Shibata, Y. and Miyazaki, T. (2005) Anode Glow Discharge Plasma Treatment of Titanium Plates Facilitates Adsorption of Extracellular Matrix Proteins to the Plates. Journal of Dental Research, 84, 668-671. http://dx.doi.org/10.1177/154405910508400717

[27] Shibata, Y., Hosaka, M., Kawai, H. and Miyazaki, T. (2002) Glow Discharge Plasma Treatment to Titanium Plates Enhances Adhesion of Osteoblast-Like Cells to the Plates through the Integrin-Mediated Mechanism. The International Journal of Oral Maxillofac Implants, 17, 771-777. 